(C) 2022, The Authors. Published by Elsevier Inc. and Fass Inc. on behalf of the American Dairy Science Association ${ }^{\circledR}$. This is an open access article under the CC BY license (http://creativecommons.org/licenses/by/4.0/).

\title{
Analysis of the complete genome sequence of Lactobacillus delbrueckii ssp. bulgaricus with post-acidification capacity and its influence on yogurt in storage
}

\author{
Yingxue Yue, ${ }^{1 *}$ Song Wang, ${ }^{1 *}$ Xiuli Lv, ${ }^{1}$ Chengfeng Wang, ${ }^{1}$ Baofeng Xu, ${ }^{1}$ Lijun Ping, ${ }^{1}$ Jiayao Guo, ${ }^{1}$ \\ Xuetong Li, ${ }^{1}$ Smith Etareri Evivie, ${ }^{1,2,3,4} \odot$ Fei Liu, ${ }^{1,2} \odot$ Bailiang Li, ${ }^{1,2} \dagger \odot$ and Guicheng Huo ${ }^{1,2} \dagger{ }^{\oplus}$ \\ ${ }^{1}$ Key Laboratory of Dairy Science, Ministry of Education, Northeast Agricultural University, Harbin 150030, PR China \\ ${ }^{2}$ Food College, Northeast Agricultural University, Harbin 150030, PR China \\ ${ }^{3}$ Department of Food Science and Human Nutrition, Faculty of Agriculture, University of Benin, Benin City 300001, Edo State, Nigeria \\ ${ }^{4}$ Department of Animal Science, Faculty of Agriculture, University of Benin, Benin City 300001, Edo State, Nigeria
}

\begin{abstract}
In recent years, yogurt has been one of the most popular fermented dairy products and is sold worldwide. In this study, $\mathrm{pH}$ and titrated acid changes of 4 strains of Lactobacillus delbrueckii ssp. bulgaricus fermented milk during storage were detected. The difference between L. bulgaricus KLDS1.1011 and KLDS1.0207 was significant, with the latter exhibiting reduced acidity levels. Therefore, we determined the complete genome sequence of the 2 strains. Then the expression of specific genes and common genes related to glucose metabolism and proteolysis of L. bulgaricus KLDS1.1011 and KLDS1.0207 were detected by quantitative real-time reverse-transcription PCR. Analysis indicated that the key enzymes in glycometabolism and proteolysis of L. bulgaricus KLDS1.1011 were significantly different than those of L. bulgaricus KLDS1.0207. The contents of lactose and glucose decreased during storage of $L$. bulgaricus fermented milk, as determined by HPLC, and the contents of lactic acid and galactose increased, with L. bulgaricus KLDS1.1011 increasing less. With skim milk as a raw material, L. bulgaricus KLDS1.1011, KLDS1.0207, and Streptococcus thermophilus S1 were used as fermentation strains to yield yogurt at $42^{\circ} \mathrm{C}$, and sensory evaluation was compared with yogurt fermented by commercial starter cultures. Yogurt from $L$. bulgaricus KLDS1.1011 was the highest-rated. Therefore, the study may provide guidelines for the development of yogurt starters.
\end{abstract}

Received July 13, 2021.

Accepted October 12, 2021.

*These authors contributed equally to this work.

†Corresponding authors: 15846092362@163.com and guichenghuo@ 126.com
Key words: Lactobacillus delbrueckii ssp. bulgaricus, fermentation milk, post-acidification, glycometabolism, proteolysis

\section{INTRODUCTION}

Streptococcus thermophilus and Lactobacillus delbrueckii ssp. bulgaricus ferment milk in yogurt production (Farag et al., 2021). Lactic acid bacteria (LAB) ferment milk to produce lactic acid, which causes milk to solidify. This process prevents the original milk from spoilage and has good viscous texture characteristics, smooth taste, unique flavor, and specific probiotic characteristics (Robinson, 2002). Yogurt starter strains have a high diversity of strains, with notable differences in genome and technological properties (growth characteristics; capacity to produce acid, exopolysaccharide, and flavor compounds; protein hydrolyzation activity; and the symbiosis of strains; El-Sharoud et al., 2012). Fermented milks may then be stored at 4 to $10^{\circ} \mathrm{C}$, during which time $L$. bulgaricus mainly produces lactic acid; a large amount of lactic acid will make the yogurt taste sour. This process is called post-acidification. The rapid and effective use of carbon sources is the main factor in rapid acid production and $\mathrm{pH}$ decrease. The post-acidification differences shown by Lactobacillus acidophilus NCDO 1748 and Lactobacillus bifidus NCDO 11863 are directly related to their lactose metabolism. In yogurt, about $400 \mathrm{mg} / 100 \mathrm{~g}$, or about $40 \%$, of the total lactic acid was the D (-) isomer (Alm, 1982).

Lactobacillus delbrueckii ssp. bulgaricus is a bacteria that causes post-acidification of yogurt because of acid resistance (Wang et al., 2013). Lactobacillus delbrueckii ssp. bulgaricus has a higher protein hydrolyzation activity, which indicates that the proteolytic enzymes of L. bulgaricus could participate in metabolism during 
the late stage of milk fermentation (El-Zahar et al., 2003). The best approach to limiting post-acidification and still producing desirable yogurt flavor is to regulate the growth and maintenance of L . bulgaricus by controlling its energy metabolism (Oliveira et al., 2010). F0F1-ATP synthase $\left(\mathrm{H}^{+}\right.$-ATP synthase) is one of the critical enzymes in the energy metabolism of LAB, which makes anaerobic bacteria excrete protons through ATP hydrolysis and regulate and maintain normal pH in cells (Chuah and Mao, 2020). Lactic acid bacteria produce first pyruvate through the glucose degradation pathway and then lactic acid through the action of lactate dehydrogenase (Even et al., 1999). Pyruvate is an essential intermediate product of glycometabolism, and lactate dehydrogenase is crucial for lactic acid production. It is generally believed that the D-lactic acid content is high in yogurt during storage. The yogurt shows a serious post-acidification phenomenon, which indicates that D-lactate dehydrogenase significantly influences the post-acidification of yogurt. Le Bras and Garel (1991) concluded that the D-lactate dehydrogenase of $L$. bulgaricus was structurally similar to other LAB but had no homology with L-lactate dehydrogenase. The mechanism of $L$. bulgaricus affecting post-acidification of yogurt in glucose metabolism was further elucidated.

Lactic acid bacteria cannot synthesize some amino acids because they lack essential amino acid metabolic pathways (Fernández and Zúñiga, 2006). Therefore, LAB need to obtain the corresponding active substances from the external environment. A proteolysis system can hydrolyze casein to supply the peptides and amino acids needed for physiological metabolism. At the same time, the metabolism of some amino acids can be further converted into aldehydes and alcohols, which play an important role in the formation of flavor substances in fermented dairy products (Liu et al., 2010). The casein hydrolysis process can be divided into 3 stages. First, casein in the dairy product is hydrolyzed into peptide substances by extracellular protease. Then the Opp system transfers peptides into the cell. Finally, free amino acids are formed by intracellular peptidases (dipeptidase, carboxypeptidase, and endopeptidase) entering the metabolic pathway or synthesizing proteins for bacterial use. The Opp system is an integral part of the proteolytic system, consisting of a membrane-anchored oligopeptide binding protein (OppA), 2 proteins responsible for the transmembrane transport (OppB and $\mathrm{OppC}$ ), and 2 ATP binding proteins (OppD and OppF; Simov and Ivanov, 2005). Therefore, this work analyzes the glycometabolism and proteolysis genes of $L$. bulgaricus and then evaluates the storage quality of fermentation milk, aiming to provide a theoretical basis for developing yogurt with better taste and better storage quality.

\section{MATERIALS AND METHODS}

\section{Bacterial Strains}

Lactobacillus delbrueckii ssp. bulgaricus KLDS1.0207 and KLDS1.1011 and Strep. thermophilus S1 were stored in the Key Laboratory of Dairy Science of Northeast Agricultural University (Harbin, China). Lactobacillus delbrueckii ssp. bulgaricus KLDS1.0207 and KLDS1.1011 were cultured in de Man, Rogosa, and Sharpe (MRS) broth, and Strep. thermophilus S1 was cultured in M17 broth (Qingdao Hope Bio-Technology Co. Ltd.). Strains were grown in MRS broth at $37^{\circ} \mathrm{C}$ under static conditions and collected by centrifugation $\left(6,000 \times g\right.$ at $4^{\circ} \mathrm{C}$ for $\left.5 \mathrm{~min}\right)$, and L. bulgaricus KLDS1.0207 and KLDS1.1011 were added to sterilized skim milk at $4 \%$ respectively. Milk was kept in the constant-temperature incubator until curd at $42^{\circ} \mathrm{C}$. Then the fermented milks were stored at $4^{\circ} \mathrm{C}$ for determination of $\mathrm{pH}$, quantitative real-time reverse-transcriptionPCR, and determination of protein hydrolysis activity.

\section{pH and Titrated Acid in Milk Fermented by a Single Strain and Mixed Strains Assay}

Fresh skim milk was put in a $65^{\circ} \mathrm{C}$ water bath, and white sugar was added at $5 \%$ by volume. The temperature was raised to $95^{\circ} \mathrm{C}$ for $10 \mathrm{~min}$ to sterilize when the milk was mixed, and then the milk was taken out and placed at room temperature for cooling. Lactobacillus delbrueckii ssp. bulgaricus KLDS1.1011, L. bulgaricus KLDS1.0207, L. bulgaricus KLDS1.1011 + Strep. thermophilus S1, L. bulgaricus KLDS1.0207 + Strep. thermophilus S1 (1:1) and Chr. Hansen strains (L. bulgaricus, Strep. thermophilus, Bifidobacterium, L. acidophilus; $5.6 \times 10^{6} \mathrm{cfu} / \mathrm{mL}$ ) were added into milk respectively and fermented at $42^{\circ} \mathrm{C}$ for $5 \mathrm{~h}$. The fermented milk was placed at $4^{\circ} \mathrm{C}$ for $12 \mathrm{~h}$ for ripening and stored at $4^{\circ} \mathrm{C}$ for $21 \mathrm{~d}$. We measured $\mathrm{pH}$ using a $\mathrm{pH}$ meter, and the content of titration acidity was measured according to GB 5009.239-2016 (National Standard for Determination of Food Acidity) according to Hang et al. (2020).

\section{Whole-Genome Sequencing}

The genomes of L. bulgaricus KLDS1.0207and $L$. bulgaricus KLDS1.1011 were sequenced and compared. Illumina HiSeq $(2 \times 100$ bp paired-end library $)$ and Illumina MiSeq $(2 \times 250$ bp paired-end library) plat- 
form combinatorial sequencing technology were used to sequence the genomes of 2 strains (Chin et al., 2013). Canu (v. 2.1.1, Celera Assembler) and Unicycler (SPAdes 3.13.0, Center for Algorithmic Biotechnology) were used to assemble the samples, respectively, to obtain the preliminary assembly results. The preliminary results were compared, the 3 assembly sequences and mutually verified with the known sequences of $L$. bulgaricus, such as L. bulgaricus ATCC11842, to obtain the final assembly results. The complete genome sequences of L. bulgaricus KLDS1.0207 and L. bulgaricus KLDS1.1011 were submitted to the GenBank database, and the accession numbers are CP032451.1 and CP041280.1, respectively. Genome annotation was performed using the NCBI Prokaryotic Genome Annotation Pipeline (http://www.ncbi.nlm.nih.gov/books/ NBK174280). The CGView Server (http://cgview.ca/ ) was used to draw a circular genome map (Wu et al., 2011).

\section{COG and KEGG Annotations}

The protein sequence in the genome was annotated with Clusters of Orthologous Groups (COG) through the Web MGA website (Wu et al., 2011; http://weizhong -lab.ucsd.edu/webMGA/). OrthoMCL v. 1.4 software (VEuPathDB) was used to perform homologous cluster analysis on L. bulgaricus KLDS1.0207 and L. bulgaricus KLDS1.1011 sequences (Farrer, 2017) and to obtain the unique genes, respectively. Kyoto Encyclopedia of Genes and Genomes (KEGG) online annotations were used for protein-coding genes in the unique genome, using the bi-directional best hit method on the KAAS website (Moriya et al., 2007; https://www.genome.jp/ tools/kaas/). All biological pathway information related to genes was stored in the PATHWAY database (https: //www.kegg.jp/kegg/pathway.html), including lactose metabolism and proteolytic pathways. Each gene's biological pathways were obtained through KEGG orthology, and KEGG pathway analysis was performed (Kanehisa et al., 2016).

\section{Real-Time Reverse-Transcription PCR Assay}

Bacterial RNA in fermented milk was extracted using Trizol reagent (Invitrogen; Lim et al., 2020). According to the manufacturer's protocol, the RNA extracted from yogurt was reversed transcribed into cDNA using the PrimeScript RT reagent kit (TaKaRa). Expression of target genes was determined using the QuantStudio 3 Real-Time PCR system (Applied Biosystems) with TB Green Premix Ex TaqII (TaKaRa). The $2^{-\Delta \Delta \mathrm{Ct}}$ method was used to calculate the relative expression of target genes, with $16 \mathrm{~S}$ rRNA serving as an endogenous gene (Marco and Kleerebezem, 2008). The sequences of primers are listed in Supplemental Table S1 (https: $/ /$ mfr.osf.io/render?url=https $\% 3 \mathrm{~A} \% 2 \mathrm{~F} \% 2 \mathrm{Fosf}$.io $\% 2$ Fc7495\%2Fdownload).

\section{Contents of Lactose, Galactose, Glucose, and Lactic Acid Assay}

Fermented milk was treated using the Carrez method (Sun et al., 2012). First, $5 \mathrm{~g}$ of milk fermented by a single strain was dissolved in $25 \mathrm{~g}$ of water. Then 2.5 $\mathrm{mL}$ of the Carrez I solution and the Carrez II solution was added into the mixture, and water was added to make up a weight of $50 \mathrm{~g}$. Then, the solution was placed on a magnetic stirrer and stirred for $30 \mathrm{~min}$ and centrifuged for $15 \mathrm{~min}(4,000 \times g)$ to obtain the supernatant, and the proteins and bacteria were removed by filtering with a $0.22-\mu \mathrm{m}$ microporous membrane. Finally, the fermented milks were stored at $-20^{\circ} \mathrm{C}$. The contents of lactose, galactose, glucose, and lactic acid were determined by HPLC. Samples of $1.5 \mathrm{~mL}$ of the fermented milk were taken at $0 \mathrm{~d}, 6 \mathrm{~d}, 12 \mathrm{~d}$, and 18 $\mathrm{d}$ and centrifuged for $10 \mathrm{~min}(9,000 \times g)$, then the supernatant was filtered with a $0.22-\mu \mathrm{m}$ microporous membrane. The filtrate was placed in the fermentation milk bottle for analysis, and 3 parallel sets were used in each group. For HPLC analysis an HPX-87H column (Waters Corp.) was used, with an RID2414 refractive index detector (Waters Corp.). The mobile phase was $5 \mathrm{mmol} / \mathrm{L} \mathrm{H}_{2} \mathrm{SO}_{4}$, and the flow rate was $0.6 \mathrm{~mL} / \mathrm{min}$. The temperature was $65^{\circ} \mathrm{C}$, and the injection volume was $2 \mu \mathrm{L}$. The time of detection for each fermentation milk was 20 min. Standard samples were prepared with mobile phase as solvent at 5 different concentration levels $(4,6,8,10$, and $12 \mathrm{mg} / \mathrm{mL}$ of lactose; $1,2,3,4$, and $5 \mathrm{mg} / \mathrm{mL}$ of galactose; $0.5,1.0,1.5,2.0$, and 2.5 $\mathrm{mg} / \mathrm{mL}$ of glucose; and $0.5,1.0,1.5,2.0$, and $2.5 \mathrm{mg} /$ $\mathrm{mL}$ of lactic acid). The standard samples were filtered through a $0.22-\mu \mathrm{m}$ microporous membrane and placed in sample bottles. The standard curve can be plotted using the peak area as the abscissa and the content of the standard sample $(\mathrm{mg} / \mathrm{mL})$ as the ordinate (Ohlsson et al., 2017).

\section{Capacity of Strain to Hydrolyze Protein Assay}

The capacity of each strain to hydrolyze protein was determined via the $o$-phthaldialdehyde (OPA) method (Rohm et al., 1996). First, $80 \mathrm{mg}$ of OPA was dissolved in $2 \mathrm{~mL}$ of methanol, and then $50 \mathrm{~mL}$ of sodium tetraborate $(100 \mathrm{mmol} / \mathrm{L}), 5 \mathrm{~mL}$ of $\operatorname{SDS}(20 \%$, wt/wt), and $200 \mu \mathrm{L}$ of $\beta$-mercaptoethanol were added. Finally, 
distilled water was added to make up the final volume of $100 \mathrm{~mL}$ to prepare the OPA solution. Three milliliters of a single-strain fermented milk stored at low temperature was added, with $6 \mathrm{~mL}$ of trichloroacetic acid $(0.75$ $\mathrm{mol} / \mathrm{L}$ ) and $0.6 \mathrm{~mL}$ of distilled water. The mixture was evenly mixed and rested at room temperature for 10 min. The supernatant was centrifuged $(6,000 \times g)$ to collect supernatant and filtered for later use. Five Lphenylalanine standard solutions with different concentrations were prepared $(1,2,4,6$, and $32 \mathrm{mmol} / \mathrm{L})$, and $0.3 \mathrm{~mL}$ of L-phenylalanine standard solution at each of the 5 concentrations were taken respectively and were added into $6 \mathrm{~mL}$ of OPA to mix evenly. A standard curve can be plotted using the concentration of leucine as the abscissa and absorbance as the ordinate. Five milliliters of the supernatant of the fermented milk was taken, and $46 \mu \mathrm{L}$ of OPA was added to it. After the mixture was evenly mixed, it was allowed to react at room temperature for $2 \mathrm{~min}$, and its absorbance was measured at the wavelength of $340 \mathrm{~nm}$ with a UV-Vis spectrophotometer (Macy China Instruments Inc.).

\section{Determination of Yogurt Texture and Water-Holding Capacity}

Quality of yogurt was evaluated following the method described by Saleh et al., using a texture analyzer (TAXT Plus, Texture Technologies; Saleh et al., 2020) with parameters as follows: distance of the probe A/BE-d35 into the fermentation milk: $30 \mathrm{~mm}$; disk diameter: 35 $\mathrm{mm}$; fixture: TA-BT-KI; trigger point load: $7 \mathrm{~g}$; deformation rate: $50 \%$; cycles: 2 ; speed in the pretest: 2 $\mathrm{mm} / \mathrm{s}$; speed in the test: $1 \mathrm{~mm} / \mathrm{s}$; return speed: $1 \mathrm{~mm} / \mathrm{s}$. Each fermentation milk was repeated 5 times and then the results were averaged. Twenty people with professional sensory evaluation knowledge were selected to evaluate the ripened yogurt, and the yogurt was scored according to the scorecard system by which the USDA scored Swiss yogurt (Bodyfelt and Potter, 2008). The evaluation was carried out from 6 aspects of taste, smell, texture, appearance, level of popularity, and whey separation to further verify the effects of 2 strains of $L$. bulgaricus with significant post-acidification differences on the overall flavor of yogurt (Supplemental Table S2; https://mfr.osf.io/render?url=https\%3A\%2F $\% 2$ Fosf.io\%2Fc7495\%2Fdownload). Water-holding capacity of the fermented milks was determined by the method of Yekta and Ansari (2019), with a few modifications. Briefly, the fermentation milks $(10 \mathrm{~g})$ were centrifuged at $6,000 \times g$ for $10 \mathrm{~min}$ at $4^{\circ} \mathrm{C}$ to separate the supernatant (whey) and drained gel (precipitate). The following equation was used to calculate waterholding capacity:

$$
\text { WHC }(\%)=\frac{\text { Weight of precipitate }(\mathrm{g})}{\text { Weight of fermented milk }(\mathrm{g})} \times 100 .
$$

\section{Statistical Analysis}

Data listed in this paper are the average of at least 3 samples, and the experimental results are presented as average \pm standard deviation. One-way ANOVA and independent sample $t$-test were analyzed using SPSS version 16.0 (Pallant, 2013; SPSS Inc.). Data were processed and plotted using Origin version 8.0 (OriginLab). In all results, $P<0.05$ was considered to be significant.

\section{RESULTS}

\section{Analysis of PH and Titrated Acid Changes}

Skim milk was fermented by 4 strains of $L$. bulgaricus, and the $\mathrm{pH}$ and titrated acid changes during the fermented milk's storage period were determined. The results showed that $\mathrm{pH}$ decreased significantly and acidity increased significantly from 0 to $9 \mathrm{~d}$ of storage for the $4 \mathrm{~L}$. bulgaricus strains, and the postacidification capacities of the milk fermented by the 4 strains were different. The results indicated that 0 to $9 \mathrm{~d}$ was the critical period for $L$. bulgaricus to cause post-acidification in yogurt, mainly because the living bacteria in fermented milk continue to use lactose to produce acid. The order of post-acidification capacity was as follows: L. bulgaricus KLDS1.0207 > KLDS1.0205 > KLDS1.1001 > KLDS1.1011. The pH and titrated acid levels of $L$. bulgaricus KLDS1.0207 changed the most during the storage period, and $L$. bulgaricus KLDS1.1011 changed the least. The $\mathrm{pH}$ decreased to 3.92 and 4.3, respectively (Figure 1A), and the titratable acidity increased by $60^{\circ} \mathrm{T}$ and $15^{\circ} \mathrm{T}$, respectively, after $21 \mathrm{~d}$ (Figure 1B). However, the $\mathrm{pH}$ and titrated acid changes of L. bulgaricus KLDS1.0205 were similar to those of L. bulgaricus KLDS1.1001. The results showed that L. bulgaricus KLDS1.0207 had higher post-acidification capacity than L. bulgaricus KLDS1.011.

\section{Genome Analysis}

Genome Composition. The genome of L. bulgaricus KLDS1.0207 consists of a circular chromosome $(1,869,179 \mathrm{bp})$ with a $\mathrm{G}+\mathrm{C}$ content of $39.72 \%$ and no plasmids. A total of 2,059 genes were predicted in the genome, with a total length of 1,608, $390 \mathrm{bp}$. The total length of coding regions accounted for $86.05 \%$ of the whole genome, and the average length of coding 
A

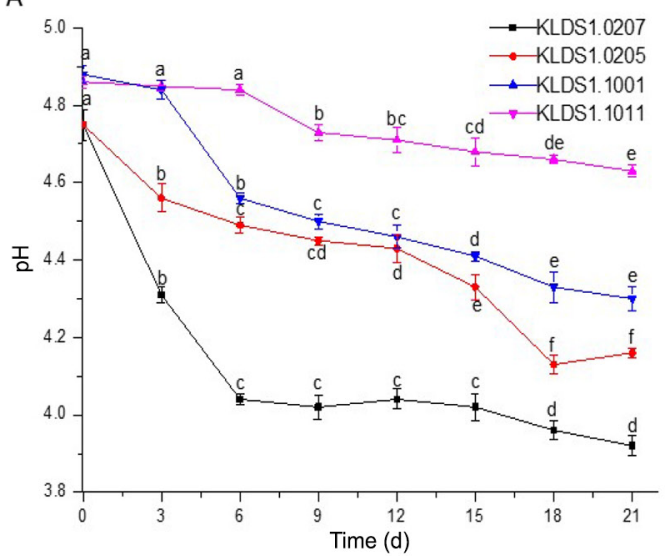

B

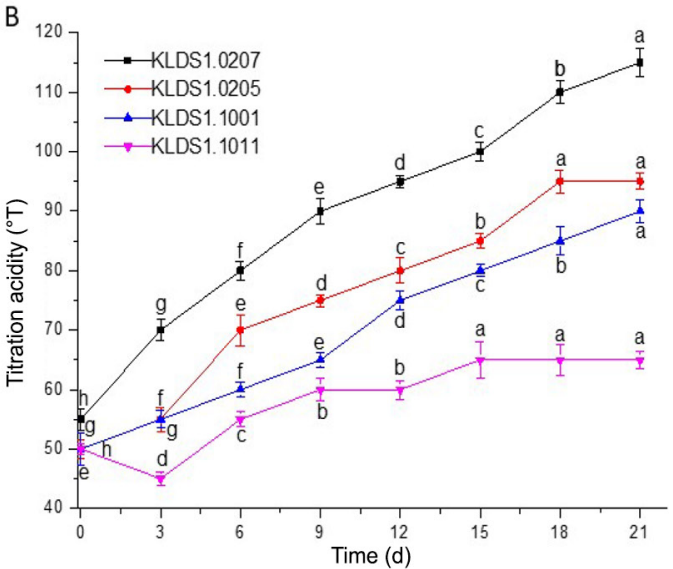

Figure 1. $\mathrm{pH}(\mathrm{A})$ and titration acidity curves (B) of single-strain fermented milks during storage. Milks were fermented with starter strains of Lactobacillus delbrueckii ssp. bulgaricus: KLDS1.0207, KLDS1.0205, KLDS1.1011, and KLDS1.1001. Different lowercase letters indicate significant differences across time $(P<0.05)$. Error bars represent SD.

genes is $781 \mathrm{bp}$. In addition, we found 96 tRNA, with a total length of $7,250 \mathrm{bp}$, accounting for $0.3879 \%$ of the genome. The genome of L. bulgaricus KLDS1.1011 consists of a circular chromosome $(1,887,491 \mathrm{bp})$ with a $\mathrm{G}+\mathrm{C}$ content of $39.83 \%$. A total of 2,098 genes were predicted in the genome, with a total length of 1,622,760 bp. The total length of coding regions accounted for $85.97 \%$ of the whole genome. The average length of coding genes was $773 \mathrm{bp}$. Moreover, the total length of 95 tRNA of $7,187 \mathrm{bp}$ accounts for $0.3808 \%$ of the genome. The genomes of 2 strains have $27 \mathrm{rRNAz}$ [9 (5s), 9 (16s), and 9 (23s)] gene operons without sRNA (Figure 2).

Analysis of COG and KEGG Pathways. The COG annotation was performed on the protein-coding genes with biological functions in the genome of $L$. bulgaricus KLDS1.0207 and L. bulgaricus KLDS1.1011 through the WebMGA website. Lactobacillus delbrueckii ssp. bulgaricus KLDS1.0207 has a total of 1,426 genes with biological function annotation classification, which are $2,53,23,171,82,107,54,44,175,86,80,91$, $4,45,59,13,105,56,64,12,47,1$, and 52 genes, annotated into COG classifications B to X, respectively, with strains annotated to carbohydrate transport and metabolism (7.50\%), amino transport and metabolism (11.99\%), and unknown functional protein (3.92\%). Lactobacillus delbrueckii ssp. bulgaricus KLDS1.1011 has a total of 1,258 protein-coding genes annotated in the COG database, with $40,20,134,83,75,46,44$, $172,75,76,80,4,45,59,13,94,54,55,13,33,1$, and 42 genes annotated into COG classifications c to $\mathrm{x}$, respectively, of which carbohydrate transport and
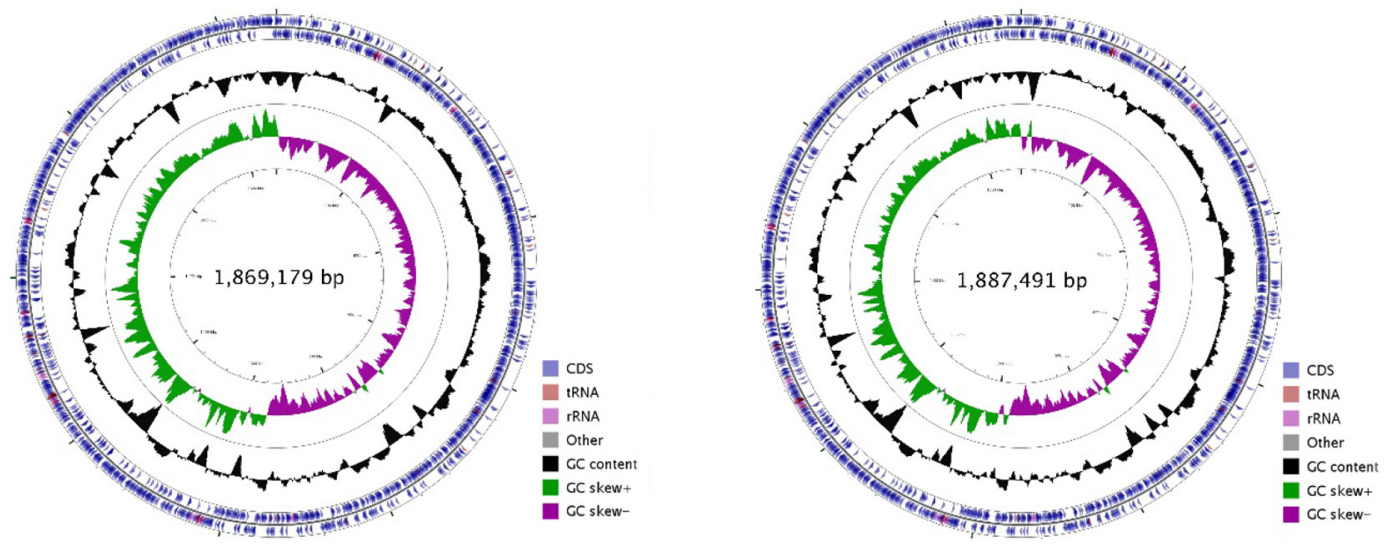

Figure 2. Circular genome map of Lactobacillus delbrueckii ssp. bulgaricus KLDS1.0207 and L. bulgaricus KLDS1.1011. From the outer circle to the inner circle, the first and second circles represent genes on the positive and negative strands, respectively, including coding sequences, transfer (t)RNA, rRNA, and other genes; the third circle represents GC content; the fourth circle represents GC skew, where green means GC $>0$, purple means GC $<0$, and the junction of green and purple is the start point and end point of replication, respectively. 
metabolism $(5.96 \%)$, amino transport and metabolism (10.65\%), and unknown functional proteins (4.29\%) have a large number of genes (Figure 3A).

The specific genes of L. bulgaricus KLDS1.0207 and $L$. bulgaricus KLDS1.1011 were annotated in the KEGG pathway; the distribution of genes related to acid production is shown in Figure 3B. Lactobacillus delbrueckii ssp. bulgaricus KLDS1.0207 and L. bulgaricus KLDS1.1011 have 15 and 7 specific genes in the carbohydrate metabolism system, respectively. Lactobacillus delbrueckii ssp. bulgaricus KLDS1.0207 and KLDS1.1011 have 12 and 7 specific genes involved in the proteolysis amino acid metabolism pathway, respectively. In addition, 6 genes specific to membrane trans- port pathways were found in L. bulgaricus KLDS1.0207 and 13 specific genes in L. bulgaricus KLDS1.1011. These specific genes were annotated to the pathway and require further preliminary screening and determination.

\section{Expression of Specific and Common Genes of Strains Related to Acid Production}

The amount of gene expression of $L$. bulgaricus KLDS1.1011 in yogurt during the storage period is shown in Figure 4A. After 6-d storage, the gene expression of FG480_01235, FG480_03790, FG480_09835, FG480_03785, FG480_03780, and FG480_00935 were
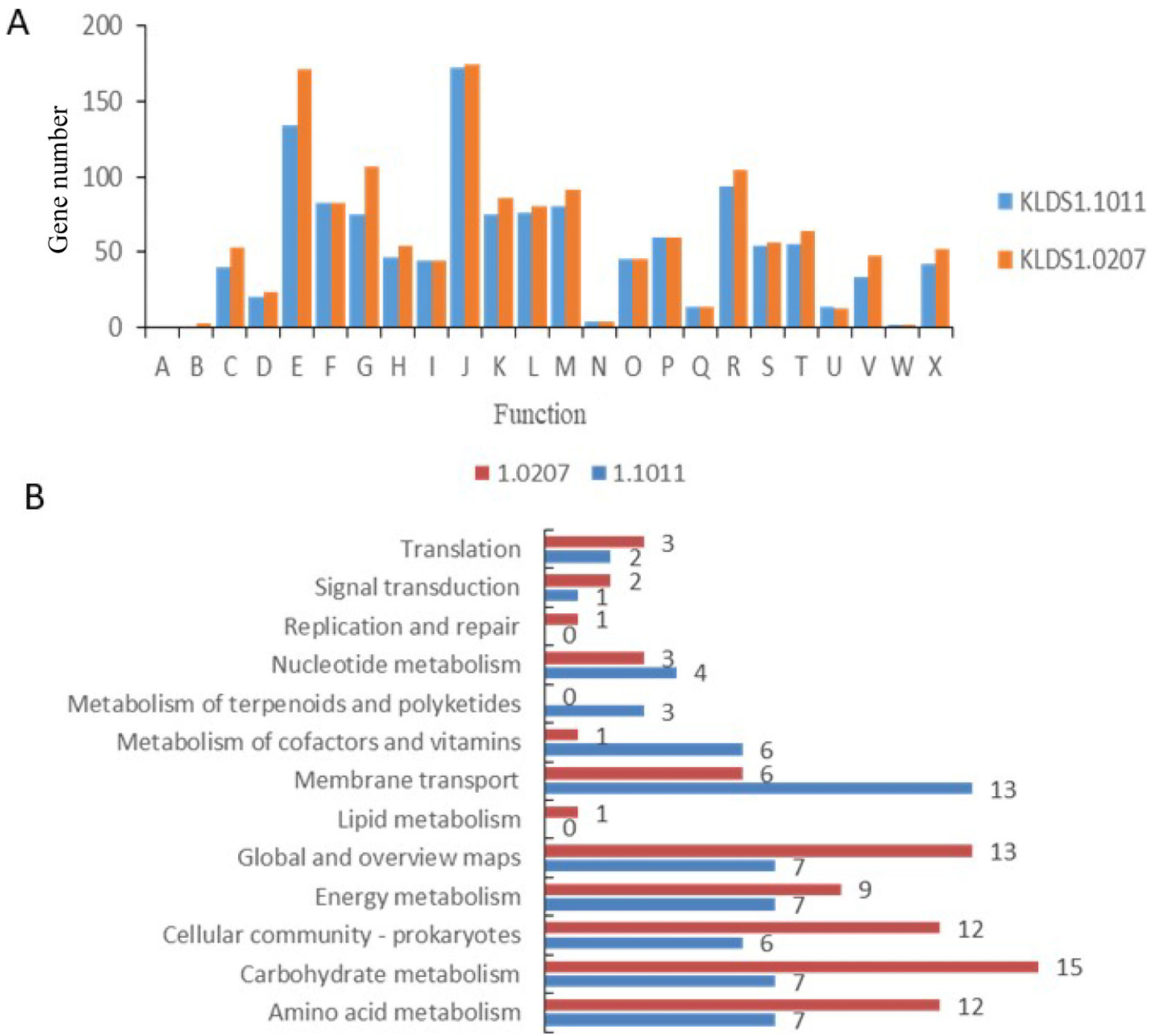

Figure 3. (A) Clusters of Orthologous Groups functional classification of protein-coding genes in the Lactobacillus delbrueckii ssp. bulgaricus KLDS1.0207 and L. bulgaricus KLDS1.1011 genomes. Function: A = RNA processing and modification; $\mathrm{B}=$ chromatin structure and dynamics; $\mathrm{C}=$ energy production and transformation; $\mathrm{D}=$ cell cycle control, cell analysis, chromosome partitioning; $\mathrm{E}=$ amino acid transport and metabolism; F = nucleic acid transport and metabolism; $\mathrm{G}=$ carbohydrate transport and metabolism; $\mathrm{H}=$ coenzyme transport and metabolism; $\mathrm{I}=$ lipid metabolism and transport; $\mathrm{J}=$ translation, ribosomal structure, and synthesis; $\mathrm{K}=$ transcription; $\mathrm{L}=$ replication, recombination, and repair; $\mathrm{M}=$ cell wall, cell membrane, and cell envelope; $\mathrm{N}=$ cell movement; $\mathrm{O}=$ post-translational modification, protein conversion, chaperone protein; $\mathrm{P}=$ inorganic ion transport and metabolism; $\mathrm{Q}=$ secondary metabolite synthesis, transport, and catabolism; $\mathrm{R}=$ general function prediction; $\mathrm{S}=$ unknown function; $\mathrm{T}=$ signal transduction mechanism; $\mathrm{U}=$ intracellular transport and secretion; $\mathrm{V}=$ defense system; $\mathrm{W}=$ extracellular structure; $\mathrm{X}=$ phage, transposon. (B) Kyoto Encyclopedia of Genes and Genomes pathway classification of specific genes in $L$. bulgaricus KLDS1.0207 and L. bulgaricus KLDS1.1011 genomes. 

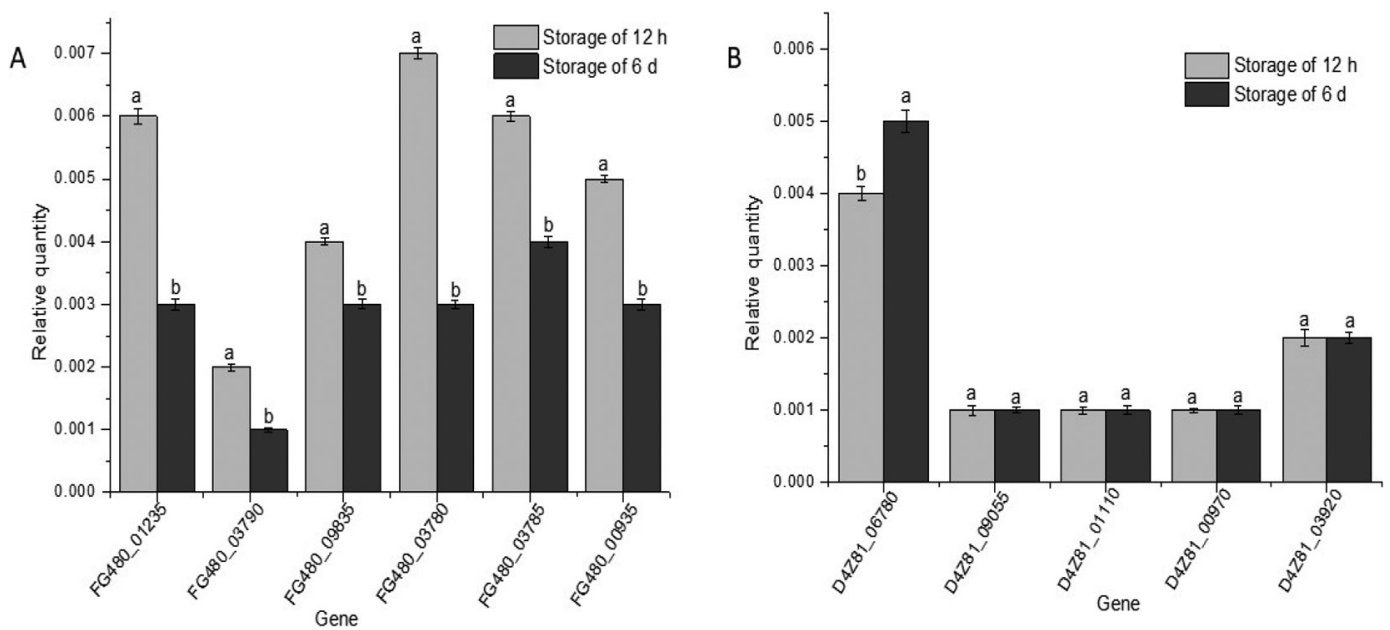

Figure 4. Relative expression of specific genes of Lactobacillus delbrueckii ssp. bulgaricus KLDS1.1011 (A) and L. bulgaricus KLDS1.0207 (B). Different lowercase letters indicate significant difference between storage times $(P<0.05)$. Error bars represent SD.

significantly lower than at $12 \mathrm{~h}(P<0.05)$. The amount of gene expression of L. bulgaricus KLDS1.0207 in yogurt during storage is shown in Figure 4B. After $6 \mathrm{~d}$ of storage, the amount of gene expression of D4Z81_03920, D4Z81_09055, D4Z81_01110, and D4Z81_00970 had no significant difference compared with that at $12 \mathrm{~h}(P>$ 0.05), but the amount of expression of the D4Z81_06780 gene was higher than at $12 \mathrm{~h}(P<0.05)$.

The expression of genes of key enzymes in lactose metabolism of L. bulgaricus KLDS1.1011 and KLDS1.0207 were different during storage, as shown in Figure 5. Both strains had 1 LacZ-coding gene, and we observed 1 ldhL-coding gene in L. bulgaricus KLDS1.1011 and 2 in L. bulgaricus KLDS1.0207 (Table 1). The LacZ and $l d h L$ gene expression levels of L bulgaricus KLDS1.0207 were significantly higher at $6 \mathrm{~d}$ of storage than at 12 $\mathrm{h}(P<0.05$; Figure 5A). However, the amount of $l d h L$ gene expression of L. bulgaricus KLDS1.1011 was significantly lower than that at $12 \mathrm{~h}(P<0.05)$, and the amount of $L a c Z$ gene expression had no significant difference at $6 \mathrm{~d}$ storage compared with $12 \mathrm{~h}(P>0.05$; Figure 5B). The gene expression levels of $L$. bulgaricus KLDS1.0207 were higher than those of L. bulgaricus KLDS1.1011 after $12 \mathrm{~h}$ and $6 \mathrm{~d}$ of storage.

The gene expression of key enzymes of $L$. bulgaricus KLDS1.1011 and KLDS1.0207 in proteolysis ( рерC, орpD, рерF, рер $Q$, рерX, and рерT) were different during storage. Both strains had all 6 genes (Table 1). The amount of $о p p D$, pepC, pepF, and pep $X$ gene expression by L. bulgaricus KLDS1.0207 was significantly decreased $(P<0.05)$ but the amount of pep T gene significantly increased after 6 -d storage compared with 12 $\mathrm{h}(P<0.05)$, and the amount of $\operatorname{pep} Q$ gene expression had no significant difference compared with $12 \mathrm{~h}(P>$
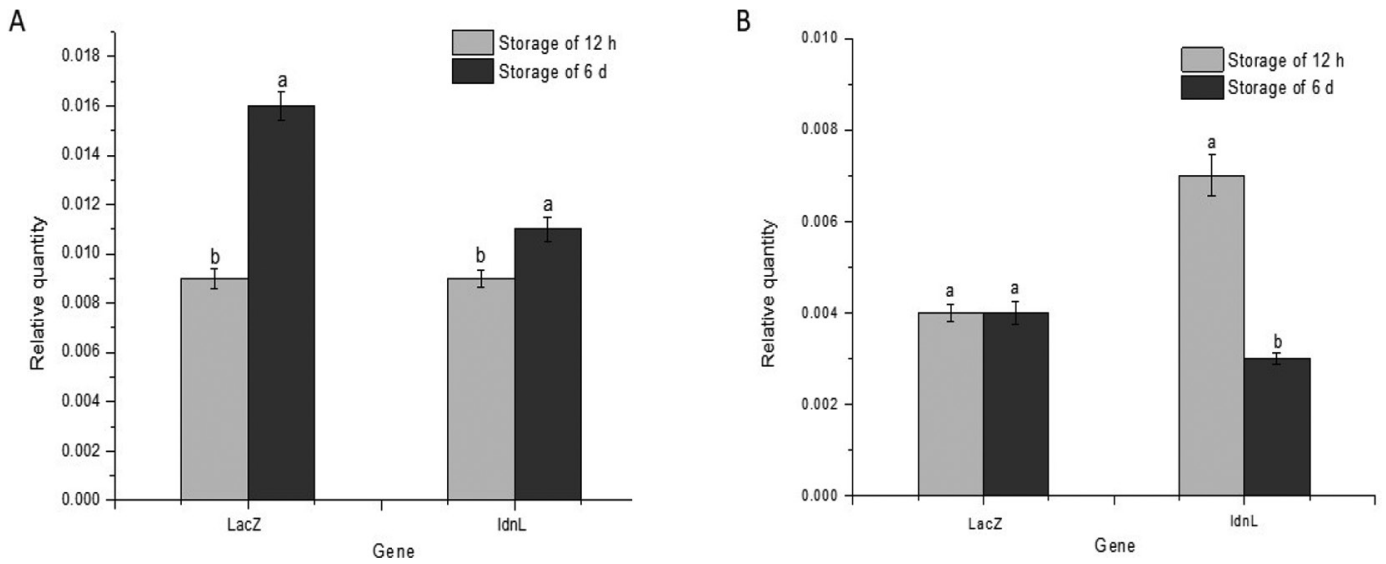

Figure 5. Relative expression of enzyme genes of Lactobacillus delbrueckii ssp. bulgaricus KLDS1.0207 (A) and L. bulgaricus KLDS1.1011 (B) related to glycometabolism. Different lowercase letters indicate significant difference between storage times $(P<0.05)$. Error bars represent SD. 

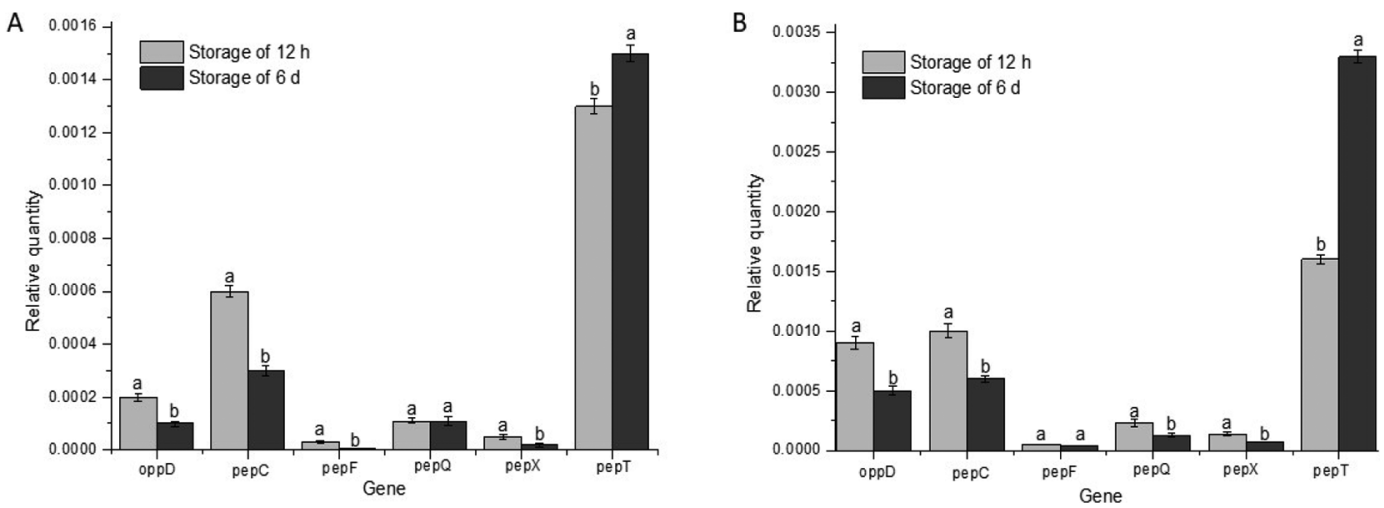

Figure 6. Relative expression of proteolytic enzyme-related genes of Lactobacillus delbrueckii ssp. bulgaricus KLDS1.0207 (A) and L. bulgaricus KLDS1.1011 (B). Different lowercase letters indicate significant differences between storage times $(P<0.05)$. Error bars represent SD.

$0.05 ;$ Figure 6A). The amount of $о p p D, \operatorname{pep} Q, \operatorname{pep} C$, and pep $X$ gene expression of $L$. bulgaricus KLDS1.1011 was significantly decreased $(P<0.05)$ after $6 \mathrm{~d}$ of storage compared with $12 \mathrm{~h}$. On the contrary, the amount of pep $T$ gene expression was significantly increased after 6 -d storage compared with $12 \mathrm{~h}(P<0.05)$, whereas pep $F$ gene expression had no significant difference compared with 12 h. (Figure 6B).

\section{Glycometabolism and Protein Hydrolyzation Capacity}

The variation of components of milk fermented by $L$. bulgaricus KLDS1.0207 and KLDS1.1011 during storage is shown in Figure 7, and the differences between strains with different capacity post-acidification can be observed. The content of lactose and glucose with $L$ bulgaricus KLDS1.0207 decreased, but the content of galactose and lactic acid increased. The content of lactose decreased significantly from 0 to $12 \mathrm{~d}(P<0.05)$. However, we found no significant difference from 12 to $18 \mathrm{~d}(P>0.05)$. No significant difference was detectable for the content of glucose from 12 to $18 \mathrm{~d}(P>0.05)$, and the contents of galactose and lactic acid increased significantly from 0 to $12 \mathrm{~d}(P<0.05)$. Lactic acid is critical to glycometabolism of $L$. bulgaricus, and it is also a factor influencing post-acidification capacity. The lactic acid content increased by $11.06 \mathrm{mg} / \mathrm{mL}$ during storage, demonstrating that L. bulgaricus KLDS1.0207 had a greater acid-producing capacity (Figure 7A). The contents of lactose and glucose with $L$. bulgaricus KLDS1.1011 decreased significantly, but the contents of galactose and lactic acid increased significantly from 0 to $12 \mathrm{~d}(P<0.05)$. The content of lactose decreased by $15.18 \mathrm{mg} / \mathrm{mL}$, glucose content decreased by 2.04 $\mathrm{mg} / \mathrm{mL}$, the content of galactose increased by 4.11 $\mathrm{mg} / \mathrm{mL}$, and lactic acid content increased by $7.04 \mathrm{mg} /$ $\mathrm{mL}$ during storage (Figure 7B). Overall, L. bulgaricus KLDS1.0207, with high post-acidification capacity, consumed $9.05 \mathrm{mg} / \mathrm{mL}$ more lactose than L. bulgaricus KLDS1.1011, with low post-acidification capacity, and produced $2.01 \mathrm{mg} / \mathrm{mL}$ more lactic acid than L. bulgaricus KLDS1.1011 during storage.

During storage, the protein hydrolyzation capacities of L. bulgaricus KLDS1.0207 and KLDS1.1011 were measured, respectively, and the results are shown in Figure 8. We found that the hydrolysis speed of $L$. bulgaricus KLDS1.0207 was high from 6 to $72 \mathrm{~h}$, with

Table 1. Key enzyme genes for glycometabolism and proteolysis of Lactobacillus delbrueckii ssp. bulgaricus KLDS1.1.0207 and L. bulgaricus KLDS1.1011

\begin{tabular}{|c|c|c|c|c|}
\hline Item & Gene & $\begin{array}{l}\text { L. bulgaricus KLDS1.1.0207 } \\
\text { Locus tag(s) }\end{array}$ & $\begin{array}{l}\text { L. bulgaricus KLDS1.1011 } \\
\text { Locus tag(s) }\end{array}$ & Product \\
\hline \multirow[t]{2}{*}{ Glucose metabolism } & LacZ & D4Z81_09625 & FG480_09590 & $\beta$-Galactosidase \\
\hline & $l d h L$ & D4Z81_04510, D4Z81_04640 & FG480_04550 & L-Lactate dehydrogenase \\
\hline \multirow[t]{6}{*}{ Proteolysis } & $o p p D$ & D4Z81_03860 & FG480_03915 & $\begin{array}{l}\text { Oligopeptide transport system } \\
\text { ATP binding protein }\end{array}$ \\
\hline & рерC & D4Z81_07205 & FG480_07235 & Bleomycin hydrolase \\
\hline & pepF & D4Z81_05850 & FG480_05910 & Oligoendopeptidase $\mathrm{F}$ \\
\hline & pepQ & D4Z81_07810, D4Z81_07820 & FG480_07385 & Xaa-Pro dipeptidase \\
\hline & pepX & D4Z81_08460 & FG480_08485 & X-Pro dipeptidyl-peptidase \\
\hline & pep T & D4Z81_03460 & FG480_03465 & Tripeptide aminopeptidase \\
\hline
\end{tabular}


A

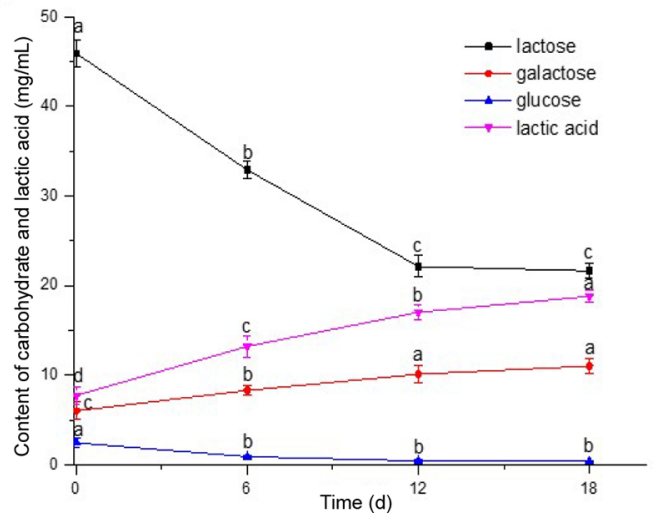

B

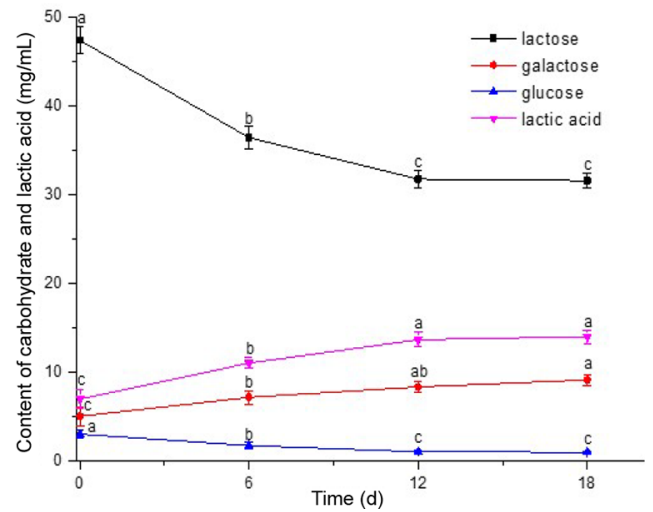

Figure 7. Glycometabolism of Lactobacillus delbrueckii ssp. bulgaricus KLDS1.0207 (A) and L. bulgaricus KLDS1.1011 (B). Different lowercase letters indicate significant differences across times $(P<0.05)$. Error bars represent SD.

a significant difference $(P<0.05)$, and low from 72 to $216 \mathrm{~h}$, with no significant differences at different times $(P>0.05)$. The hydrolysis speed of L. bulgaricus KLDS1.1011 declined during storage and showed a significant difference at 0 to $144 \mathrm{~h}(P<0.05)$. The results showed that the protein hydrolyzation capacity of L. bulgaricus KLDS1.0207 was higher than that of KLDS1.1011 from 6 to $216 \mathrm{~h}$, indicating the protein hydrolyzation of L. bulgaricus KLDS1.0207, with high post-acidification capacity, was greater than that of L. bulgaricus KLDS1.1011, with low post-acidification capacity.

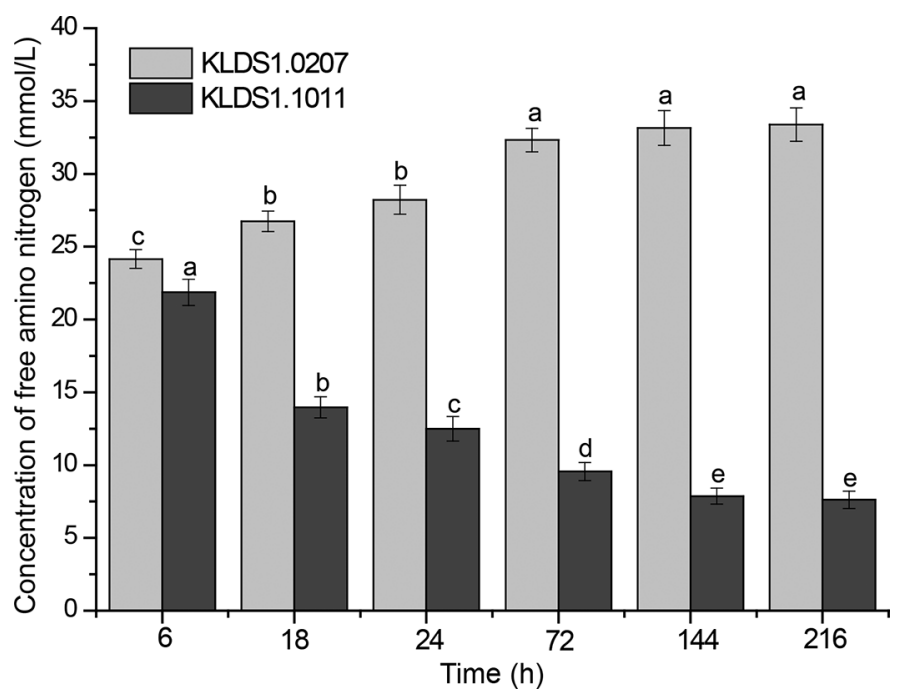

Figure 8. Assay of proteolytic activity (as concentration of free amino nitrogen) of strains Lactobacillus delbrueckii ssp. bulgaricus KLDS1.0207 and L. bulgaricus KLDS1.1011. Different lowercase letters indicate significant differences within a strain between times $(P<$ 0.05). Error bars represent SD.

\section{Analysis of the Quality of Milk Fermented With Different Starters During Storage}

The curve of pH (Figure 9A) and titrated acid (Figure 9B) of milk fermented by L. bulgaricus KLDS1.1011 + Strep. thermophilus S1, L. bulgaricus KLDS1.0207 + Strep. thermophilus S1, and Chr. Hansen (commercial starter) were determined. The acid-producing capacity of all the milks fermented by 3 different starters increased significantly in 0 to $9 \mathrm{~d}(P<0.05)$, and we observed no significant difference $(P>0.05)$ from 9 to $21 \mathrm{~d}$. The maximum titratable acidities of the milk fermented by L. bulgaricus KLDS1.1011 + Strep. thermophilus S1 and Chr. Hansen strains were $85^{\circ} \mathrm{T}$ and $95^{\circ} \mathrm{T}$, respectively. However, the maximum titratable acidity of milk fermented by L. bulgaricus KLDS1.0207 + Strep. thermophilus S1 was $110^{\circ} \mathrm{T}$.

The consistency, solidity, viscosity index, cohesiveness, and water-holding capacity were determined by a texture analyzer (Table 2). Analysis revealed significant difference in the solidity, water-holding capacity, and consistency of all the milk fermented by 3 different starters $(P<0.05)$. The water-holding capacities of milk fermented by L. bulgaricus KLDS1.1011 + Strep . thermophilus S1 and Chr. Hansen strains were similar, at about $36 \%$, and the water-holding capacity of the milk fermented by L. bulgaricus KLDS1.0207 + Strep. thermophilus S1 was $44.93 \%$. The consistency and solidity of the milk fermented by L. bulgaricus KLDS1.1011 + Strep. thermophilus S1 were the lowest, and the consistency of the milk fermented by L. bulgaricus KLDS1.0207 + Strep. thermophilus S1 was the highest. The consistency reflects the mobility of yogurt, and mobility is inversely proportional to consistency (Che et al., 2019); our results indicate that the liquidity of the milk fermented by L. bulgaricus KLDS1.1011 + Strep. thermophilus S1 was greatest, followed by the 
Table 2. Water-holding capacity and texture of fermented yogurt with different starters $^{1}$

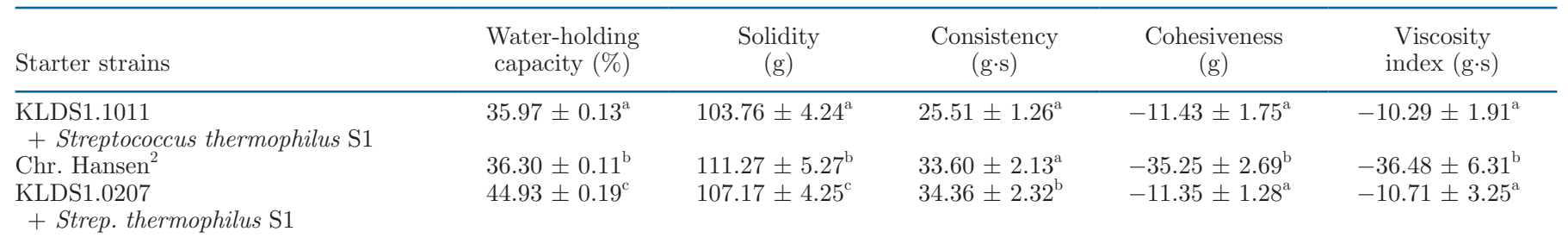

${ }^{a-c}$ Different lowercase letters indicate significant difference between different samples $(P<0.05)$.

${ }^{1}$ Values shown $\pm \mathrm{SD}$.

${ }^{2} \mathrm{Chr}$. Hansen commercial strains: Lactobacillus bulgaricus, Streptococcus thermophilus, Bifidobacterium, and Lactobacillus acidophilus.

Chr. Hansen strains, and the milk fermented by L. bulgaricus KLDS1.0207 + Strep. thermophilus S1 had the least liquidity. The viscosity index and cohesiveness are closely related to the capacity of producing viscous substances of starters. We found no significant differences in viscosity index and cohesiveness $(P>0.05)$ between the milk fermented by L. bulgaricus KLDS1.1011 + Strep. thermophilus S1 and L. bulgaricus KLDS1.0207 + Strep. thermophilus S1, but the viscosity index and cohesiveness of the milk fermented by the Chr. Hansen commercial strains were the lowest, significantly different compared with the milk fermented by the other 2 starters $(P<0.05)$.

Twenty people conducted the sensory evaluation. As shown in Figure 10, the scores of taste, smell, and texture, and the popularity of the milk fermented by $L$. bulgaricus KLDS1.1011 + Strep. thermophilus S1 were the highest; its score for the separation of whey was lower than that of the milk fermented by Chr. Hansen strains but higher than the milk fermented by L. bulgaricus KLDS1.0207 + Strep. thermophilus S1. The appearance evaluation score of the milk fermented by $L$. bulgaricus KLDS1.1011 + Strep. thermophilus S1 was the lowest and closest to that of the milk fermented by Chr. Hansen strains. The scores for taste, smell, and separation of whey for the milk fermented by $L$. bulgaricus KLDS1.0207 + Strep. thermophilus S1 were the lowest, possibly due to its high acid-producing capacity. In addition, its appearance evaluation score was the highest, but the score of milk fermented by $L$. bulgaricus KLDS1.1011 + Strep. thermophilus S1 was more popular than the milk fermented by L. bulgaricus KLDS1.0207 + Strep. thermophilus S1. In conclusion, the enjoyment of the milk fermented by $L$. bulgaricus KLDS1.1011 + Strep. thermophilus S1 was not worse than that of the milk fermented by Chr. Hansen strains, but it had some deficiencies in the separation of whey, which can be solved by adding thickener. Our experiments proved that L. bulgaricus KLDS1.1011, with low post-acidification capacity and a stable genetic sequence, had stable characteristics, could reduce the cost, created a product with acceptable taste, resulted in a texture that met consumers' requirements, and had broad market prospects.
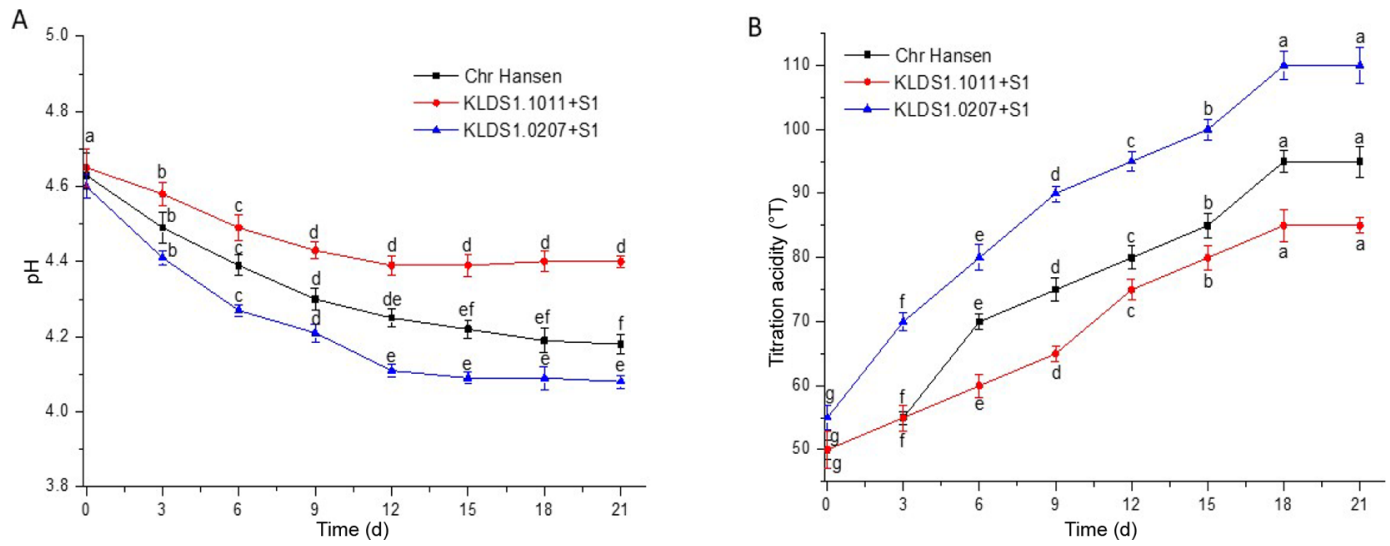

Figure 9. $\mathrm{pH}(\mathrm{A})$ and titration acidity curves (B) of milk fermented with different starter cultures: Lactobacillus delbrueckii ssp. bulgaricus KLDS1.0207, L. bulgaricus KLDS1.1011, and Chr. Hansen strains (L. bulgaricus, Streptococcus thermophilus, Bifidobacterium, and Lactobacillus acidophilus), during storage. Different lowercase letters indicate significant difference between different times $(P<0.05)$. Error bars represent SD. 


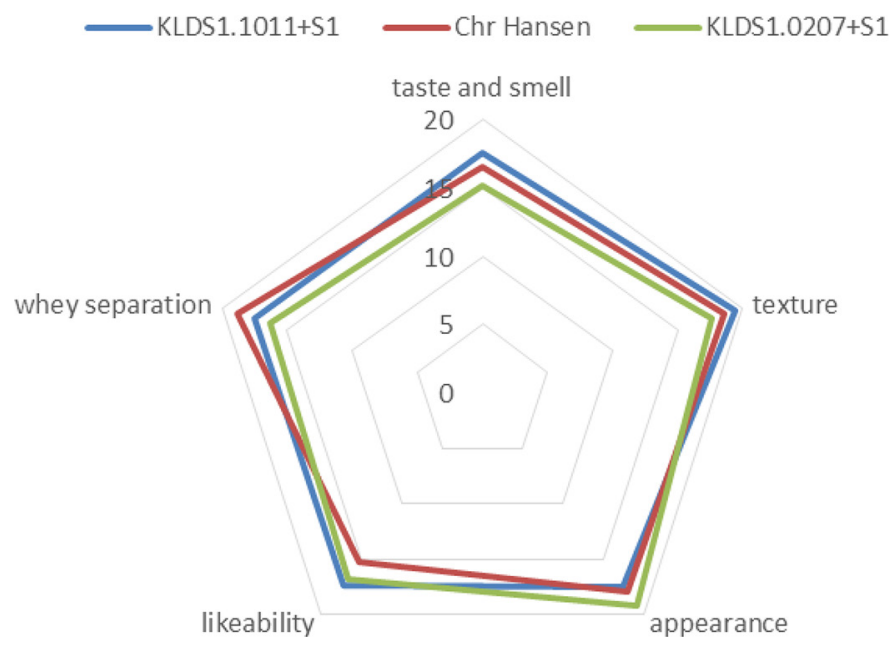

Figure 10. Sensory evaluation of fermented milk with different starters: Lactobacillus delbrueckii ssp. bulgaricus KLDS1.0207, L. bulgaricus KLDS1.1011, and Chr. Hansen strains (L. bulgaricus, Streptococcus thermophilus, Bifidobacterium, and Lactobacillus acidophilus).

\section{DISCUSSION}

The decomposition of lactose mainly causes production of lactic acid by L. bulgaricus and Strep. thermophilus during their growth, and the acidity is determined by the choice of strains, the quality of the milk, and the fermentation temperature (Jia et al., 2016; Moonga et al., 2021). The Strep. thermophilus and L. bulgaricus selected in this experiment had a good symbiotic effect. For milks fermented by a single strain and mixed strains, the $\mathrm{pH}$ and acidity of the milk fermented by L. bulgaricus KLDS1.1011 were consistently lower than that of the milk fermented by L. bulgaricus KLDS1.0207, and the results showed that L. bulgaricus KLDS1.1011 had a low post-acidification capacity. The differences in titration acidity and $\mathrm{pH}$ of yogurt lie in the different strains, mixing proportions, and acid-producing capacities of different starters (Casarotti et al., 2014).

Lactobacillus delbrueckii ssp. bulgaricus cannot metabolize pentose, but lactic acid can be produced by metabolizing lactose, glucose, and fructose through carbohydrate degradation. Lactose metabolism is the key in yogurt's post-acidification, and lactose is transported into the cell through lactose permease and decomposed to galactose and glucose by $\beta$-galactosidase (Song et al., 2016). Strains that cannot use galactose are transported out of the cell through the permease, but glucose can be transported into the carbohydrate degradation pathway through systems such as PTS and can be metabolized to produce lactic acid to control the post-acidification of yogurt (Hutkins and Nannen, 1993). Mollet et al. (2003) identified a $\beta$-galactosidase- deficient strain regulated by IS elements, which could control the post-acidification of yogurt because it could not metabolize lactose to produce lactic acid in the milk. A study has shown that the $\beta$-galactosidase gene has strong activity at $40^{\circ} \mathrm{C}$ by mutation, but the activity was weakened or even lost during storage (Benbadis et al., 2005). Therefore, the post-acidification of yogurt can be reduced by reducing the lactose metabolism of $L$. bulgaricus. In this study, the amount of expression of $2 \beta$-galactosidase genes ( $L a c Z$ and $l d h L$ ) of $L$. bulgaricus KLDS1.0207 increased in 2 periods of yogurt storage. However, the ldhL gene of L. bulgaricus KLDS1.1011 decreased after $12 \mathrm{~h}$, suggesting that the expression of genes related to the post-acidification capacity of the 2 strains during 2 different storage periods was significantly different. These 2 genes may be the key to the difference in acidification of L. bulgaricus KLDS1.1011 and KLDS1.0207 after yogurt storage.

Lactobacillus delbrueckii ssp. bulgaricus cannot assimilate inorganic nitrogen sources and needs to meet its growth requirement by producing peptides and releasing free amino acids, and its proteolytic enzymes produce peptides and free amino acids by hydrolyzing casein (Cotter and Hill, 2003). Considerable differences exist in the activity of proteolytic enzymes among different L. bulgaricus. Hou et al. (2015) studied the expression of the PepD, PepB, PepC, PepF, PepQ, PepX, and $P e p T$ genes in 3 strains of $L$. bulgaricus under different conditions. The results showed that the protein supply had the least effect on the $P e p X$ gene and the strongest effect on $O p p D$ (Hou et al., 2015). In our study, the sequences of the genes $\operatorname{prt} B, \operatorname{oppD}, \operatorname{pep} C$, pepF, рер $Q$, pep $X$, and pepT, which are key in the proteolysis system, were compared between L. bulgaricus KLDS1.1011 and KLDS1.0207. The result showed a high similarity of these gene sequences between the 2 strains. At the same time, the gene expression levels in 2 milks fermented by a single strain were analyzed, revealing both that the amount of gene expression of pep $T$ increased during the storage period and that the multiple of difference is not large, suggesting that the pep $T$ gene was closely related to post-acidification but was not the key gene that caused the difference in post-acidification between the 2 strains. The amounts of expression of oppD, pepC, pepF, pepQ, and $p e p X$ after 12 -h storage were significantly different from 6 -d storage, and 2 strains had apparent differences in the multiples of difference in different periods, suggesting that these 5 genes were the key genes that cause $L$. bulgaricus KLDS1.1011 to have a lower post-acidification capacity than L. bulgaricus KLDS1.0207.

Enzyme genes involved in post-acidification are (1) the F1F0-ATPase gene cluster; (2) genes related to the 
lactose metabolism system and genes related to the pyruvate metabolism system; (3) genes related to basic amino acid metabolism and synthesis; (4) key protease genes in the proteolytic system; (5) genes related to enzymes involved in the biosynthetic metabolic pathway of cell membranes; and (6) genes related to proteins involved in ion transport, among others. Lactobacillus delbrueckii ssp. bulgaricus KLDS1.1011 had 6 key enzyme genes associated with post-acidification, and the amount of gene expression of the 6 genes decreased after the 12 -h and 6-d storage periods, which may relate to the biofilm-associated genes (FG480_03790, FG480_09835, FG480_03785, and FG480_03780), the proteolysis-associated gene (FG480_00935), and the glycometabolism-associated gene (FG480_01235) of $L$. bulgaricus KLDS1.1011. The decline of the gene expression levels of L. bulgaricus KLDS1.1011 in the critical stage of post-acidification proved that $L$. bulgaricus KLDS1.1011 had a low post-acidification capacity. Therefore, the 6 L. bulgaricus KLDS1.1011 genes were the key genes that reduce its post-acidification capacity. However, L. bulgaricus KLDS1.0207 had 5 key enzyme genes related to post-acidification. The amount of expression of the D4Z81_06780 gene after the 6-d storage period was higher than the 12-h storage period, suggesting that the D4Z81_06780 gene was key to enhancing the post-acidification capacity of $L$. bulgaricus KLDS1.0207. D4Z81_06780 is a key enzyme in the glycolysis and gluconeogenesis metabolic system, and the glycolysis pathway is the key for L. bulgaricus acid production. The other 4 genes are related to the formation of biofilms and the material transport of strains. Overall, the 11 key enzyme genes of L. bulgaricus are associated with post-acidification.

Lactose entered the cells by lactose permease and then was decomposed by $\beta$-galactosidase to produce galactose and glucose. After that, glucose entered the glycolytic pathway and was metabolized to produce lactic acid (Daryaei et al., 2010). Therefore, the contents of galactose and glucose in yogurt decreased, and the contents of galactose and lactic acid increased. The contents of lactose and glucose in yogurt were measured by Ohlsson and colleagues under different storage times and temperatures (Ohlsson et al., 2017). The results showed no significant variation for the lactose content at $4^{\circ} \mathrm{C}$, consistent with L. bulgaricus KLDS1.1011 used in our experiment, whereas for L. bulgaricus KLDS1.0207, the content of lactose changed more obviously.

The starter used in milk fermentation is generally mixed and mainly composed of Strep. thermophilus and $L$. bulgaricus. The enzyme systems between LAB are different, and the co-cultivation system is considered effective to specific fermentation (Gu et al., 2020). In a study, Wang et al. found that 4 wild Lactobacillus strains could ferment skim milk quickly and provide a unique volatile flavor for the yogurt, and the volatile flavor characteristics of the yogurt were evaluated combined with sensory analysis (Wang et al., 2018). Xu et al. (2015) analyzed 4 different acidifying strains of L. bulgaricus and their influence on the quality of yogurt. When the $4 \mathrm{~L}$. bulgaricus strains were mixed with Strep. thermophilus TA040, the fermentation times of the yogurt starter cultures LS1 and LS2 were shorter than those of the yogurt starter cultures LS3 and LS4, and the milk fermented by LS3 and LS4 had low postacidification capacity, high viscosity, and strong capacity to produce exopolysaccharides. There are 2 reasons for the increase in viscosity of milk during fermentation: one is the precipitation of casein; the other is the extracellular polysaccharide polymer produced by $L$. bulgaricus (Xu et al., 2015). In our study, L. bulgaricus KLDS1.1011 and KLDS1.0207 were used to ferment milk with Strep. thermophilus S1, which have good characteristics, respectively, compared with yogurt fermented by Chr. Hansen strains. The results showed no differences between the fermented milks, but the milk fermented by L. bulgaricus KLDS1.1011 + Strep. thermophilus S1 had a low post-acidification capacity and a high viscosity, a good texture, and it was more popular than the others and met the requirements of industrial production. Beahkova et al. found better flavor in milk fermented by mixed strains than in milk fermented by a single strain (Beshkova et al., 1998).

\section{CONCLUSIONS}

Lactobacillus delbrueckii ssp. bulgaricus is an important strain for the post-acidification of yogurt and has good acid resistance. In our study, the 2 L. bulgaricus with significant differences in post-acidification were selected. Among them, the strain KLDS1.1011 was relatively weak in $\mathrm{pH}$, acidity, glycometabolism, and proteolysis during storage of fermentation milk. The quality of the fermented milks with mixed strains showed that the fermented milk made by $L$. bulgaricus KLDS1.1011 + Strep. thermophilus S1 had the weakest post-acidification, and $L$. bulgaricus was suitable for the development of yogurt starter. Meanwhile, we may obtain even better fermented strains and provide a theoretical basis for developing yogurt starters by combining genomics methods to study strains' mechanisms.

\section{ACKNOWLEDGMENTS}

The present research work was financially supported by "Hundred, Thousand and Ten Thousand" Science and Technology Major Special Project of Heilongjiang Province: Dairy Products and Meat Processing 
(2019ZX07801; Harbin, China), the National Natural Science Foundation of China (32101919, 32072190, and 31801518; Beijing), the Heilongjiang Postdoctoral Science Foundation (LBH-Z20006; Harbin, China), the Academic Backbone Plan of the Northeast Agricultural University (No. 19YJXG10; Harbin, China), the "Young Talents" Project of Northeast Agricultural University (18QC52; Harbin, China), and the Open Research Fund for Key Laboratory of Dairy Science (Northeast Agricultural University; Harbin, China), Ministry of Education, Heilongjiang Province, China (2020-KLDS-OF-001; Harbin, China). The authors have not stated any conflicts of interest.

\section{REFERENCES}

Alm, L. 1982. Effect of fermentation on $\mathrm{L}(+)$ and $\mathrm{D}(-)$ lactic acid in milk. J. Dairy Sci. 65:515-520. https://doi.org/10.3168/jds.S0022 $-0302(82) 82228-5$.

Benbadis, L., P. Brignon, and F. Gendre. 2005. Mutant Lactobacillus bulgaricus strains free from $\beta$-galactoside activity. Gervais Danone SA. Pat no. US6875601B1.

Beshkova, D., E. Simova, G. Frengova, and Z. Simov. 1998. Production of flavour compounds by yogurt starter cultures. J. Ind. Microbiol. Biotechnol. 20:180-186. https://doi.org/10.1038/sj.jim.2900504.

Bodyfelt, F. W., and D. Potter. 2008. Creamed cottage cheese. Pages 167-190 in The Sensory Evaluation of Dairy Products. S. Clark, M. Costello, M. A. Drake, and F. Bodyfelt, ed. Springer Science \& Business Media. https://doi.org/10.1007/978-0-387-77408-4.

Casarotti, S. N., D. A. Monteiro, M. M. S. Moretti, and A. L. B. Penna. 2014. Influence of the combination of probiotic cultures during fermentation and storage of fermented milk. Food Res. Int. 59:67-75. https://doi.org/10.1016/j.foodres.2014.01.068.

Che, H. Q., L. Z. Ai, Y. J. Xia, and H. Zhang. 2019. Effects of Streptococcus thermophilus exopolysaccharide EPS333 on the quality of yogurt. Industrial Microbiology 49:25-31. https://doi.org/10 .3969/j.issn.1001-6678.2019.02.005.

Chin, C.-S., D. H. Alexander, P. Marks, A. A. Klammer, J. Drake, C. Heiner, A. Clum, A. Copeland, J. Huddleston, E. E. Eichler, S. W. Turner, and J. Korlach. 2013. Nonhybrid, finished microbial genome assemblies from long-read SMRT sequencing data. Nat. Methods 10:563-569. https://doi.org/10.1038/nmeth.2474.

Chuah, L. O., and Y. Mao. 2020. Stability assessment and improvement of a Lactobacillus plantarum mutant with low post-fermentation acidification characteristics. J. Dairy Sci. 103:7898-7907. https://doi.org/10.3168/jds.2020-18285.

Cotter, P. D., and C. Hill. 2003. Surviving the acid test: Responses of gram-positive bacteria to low $\mathrm{pH}$. Microbiol. Mol. Biol. Rev. 67:429-453. https://doi.org/10.1128/MMBR.67.3.429-453.2003.

Daryaei, H., J. Coventry, C. Versteeg, and F. Sherkat. 2010. Effects of high pressure treatment on glycolytic enzymes of Lactococcus lactis ssp. lactis, Streptococcus thermophilus and Lactobacillus acidophilus. Innov. Food Sci. Emerg. Technol. 11:245-249. https://doi.org/ 10.1016/j.ifset.2009.11.004

El-Sharoud, W. M., C. Delorme, M. S. Darwish, and P. Renault. 2012. Genotyping of Streptococcus thermophilus strains isolated from traditional Egyptian dairy products by sequence analysis of the phosphoserine phosphatase $(\operatorname{ser} B)$ gene with phenotypic characterizations of the strains. J. Appl. Microbiol. 112:329-337. https:/ /doi.org/10.1111/j.1365-2672.2011.05212.x.

El-Zahar, K., J. M. Chobert, M. Sitohy, M. Dalgalarrondo, and T. Haertlé. 2003. Proteolytic degradation of ewe milk proteins during fermentation of yoghurts and storage. Nahrung 47:199-206. https: //doi.org/10.1002/food.200390046.

Even, S., C. Garrigues, P. Loubiere, N. D. Lindley, and M. CocaignBousquet. 1999. Pyruvate metabolism in Lactococcus lactis is de- pendent upon glyceraldehyde-3-phosphate dehydrogenase activity Metab. Eng. 1:198-205. https://doi.org/10.1006/mben.1999.0120.

Farag, M. A., H. A. Saleh, S. El Ahmady, and M. M. Elmassry. 2021. Dissecting yogurt: The impact of milk types, probiotics, and selected additives on yogurt quality. Food Rev. Int. 1-17. https://doi .org/10.1080/87559129.2021.1877301.

Farrer, R. A. 2017. Synima: A Synteny imaging tool for annotated genome assemblies. BMC Bioinformatics 18:507. https://doi.org/ 10.1186/s12859-017-1939-7.

Fernández, M., and M. Zúñiga. 2006. Amino acid catabolic pathways of lactic acid bacteria. Crit. Rev. Microbiol. 32:155-183. https:// doi.org/10.1080/10408410600880643.

Gu, Y., X. Li, H. Liu, Q. Li, R. Xiao, O. E. Dudu, L. Yang, and Y. Ma. 2020. The impact of multiple-species starters on the peptide profiles of yoghurts. Int. Dairy J. 106:104684. https://doi.org/10 .1016/j.idairyj.2020.104684.

Hang, F., Y. Jiang, L. Yan, Q. Hong, W. Lu, J. Zhao, H. Zhang, and W. Chen. 2020. Preliminary study for the stimulation effect of plant-based meals on pure culture Lactobacillus plantarum growth and acidification in milk fermentation. J. Dairy Sci. 103:40784087. https://doi.org/10.3168/jds.2019-17200.

Hou, J. C., F. Liu, D. X. Ren, W. W. Han, and Y. O. Du. 2015. Effect of culturing conditions on the expression of key enzymes in the proteolytic system of Lactobacillus bulgaricus. J. Zhejiang Univ. Sci. B 16:317-326. https://doi.org/10.1631/jzus.B1400230.

Hutkins, R. W., and N. L. Nannen. 1993. pH homeostasis in lactic acid bacteria. J. Dairy Sci. 76:2354-2365. https://doi.org/10.3168/jds .S0022-0302(93)77573-6.

Jia, R., H. Chen, H. Chen, and W. Ding. 2016. Effects of fermentation with Lactobacillus rhamnosus GG on product quality and fatty acids of goat milk yogurt. J. Dairy Sci. 99:221-227. https://doi .org/10.3168/jds.2015-10114.

Kanehisa, M., Y. Sato, and K. Morishima. 2016. BlastKOALA and GhostKOALA: KEGG tools for functional characterization of genome and metagenome sequences. J. Mol. Biol. 428:726-731. https://doi.org/10.1016/j.jmb.2015.11.006.

Le Bras, G., and J.-R. Garel. 1991. Properties of D-lactate dehydrogenase from Lactobacillus bulgaricus: A possible different evolutionary origin for the D- and L-lactate dehydrogenases. FEMS Microbiol. Lett. 63:89-93. https://doi.org/10.1016/0378-1097(91)90533-g.

Lim, S.-M., N.-K. Lee, K.-T. Kim, and H.-D. Paik. 2020. Probiotic Lactobacillus fermentum KU200060 isolated from watery kimchi and its application in probiotic yogurt for oral health. Microb. Pathog. 147:104430. https://doi.org/10.1016/j.micpath.2020.104430.

Liu, M. J. R. Bayjanov, B. Renckens, A. Nauta, and R. J. Siezen. 2010. The proteolytic system of lactic acid bacteria revisited: A genomic comparison. BMC Genomics 11:36. https://doi.org/10 .1186/1471-2164-11-36.

Marco, M. L., and M. Kleerebezem. 2008. Assessment of real-time RT-PCR for quantification of Lactobacillus plantarum gene expression during stationary phase and nutrient starvation. J. Appl. Microbiol. 104:587-594. https://doi.org/10.1111/j.1365-2672.2007 .03578.x

Mollet. B., J. E. Germond, and L. Lapierre. 2003. Mobile genetic elements as tools for genetic modification of $L$. delbrueckii or $L$. helveticus. European Patent Office no. EP0965643B1. Current Assignee: Societe des Produits Nestle SA, Nestle SA. Accessed Nov. 10, 2021. https://patents.google.com/patent/EP0965643B1/en.

Moonga, H. B., S. E. Schoustra, A. R. Linnemann, J. van den Heuvel, J. Shindano, and E. J. Smid. 2021. Influence of fermentation temperature on microbial community composition and physicochemical properties of mabisi, a traditionally fermented milk. Lebensm. Wiss. Technol. 136:110350. https://doi.org/10.1016/j.lwt.2020 .110350 .

Moriya, Y., M. Itoh, S. Okuda, A. C. Yoshizawa, and M. Kanehisa. 2007. KAAS: An automatic genome annotation and pathway reconstruction server. Nucleic Acids Research 35(Suppl. 2):W182W185. https://doi.org/10.1093/nar/gkm321.

Ohlsson, J. A., M. Johansson, H. Hansson, A. Abrahamson, L. Byberg, A. Smedman, H. Lindmark-Månsson, and A. Lundh. 2017. Lactose, glucose and galactose content in milk, fermented milk and 
lactose-free milk products. Int. Dairy J. 73:151-154. https://doi .org/10.1016/j.idairyj.2017.06.004.

Oliveira, R., A. A. Casazza, B. Aliakbarian, P. Perego, M. Oliveira, and A. Converti. 2010. Co-metabolism in skimmed milk of Streptococcus thermophilus in co-cultures with Lactobacillus bulgaricus or Lactobacillus acidophilus. J. Biotechnol. 150:338. https://doi.org/ 10.1016/j.jbiotec.2010.09.357

Pallant, J. 2013. SPSS Survival Manual: A Step by Step Guide to Data Analysis Using IBM SPSS. 5th ed. Allen and Unwin.

Robinson, R. K. 2002. Fermented milks-Yogurt: Role of starter culture. Pages 529-532 in Encyclopedia of Dairy Sciences. 2nd ed. J. W. Fuquay, ed. https://doi.org/10.1016/B978-0-12-374407-4 .00190-4.

Rohm, H., E. Tschager, and D. Jaros. 1996. Determination of proteolysis in Swiss cheese: Comparison of the Kjeldahl method and a spectrophotometric OPA assay. Lebensm. Wiss. Technol. 29:191194. https://doi.org/10.1006/fstl.1996.0027.

Saleh, A., A. A. Mohamed, M. S. Alamri, S. Hussain, A. A. Qasem, and M. A. Ibraheem. 2020. Effect of different starches on the rheological, sensory and storage attributes of non-fat set yogurt. Foods 9:61. https://doi.org/10.3390/foods9010061.

Simov, Z. I., and G. Y. Ivanov. 2005. Growth and proteolytic activity of Lactobacillus delbrueckii ssp. bulgaricus and Streptococcus thermophilus in reduced sodium Kashkaval cheese. World J. Microbiol. Biotechnol. 21:1285-1289. https://doi.org/10.1007/s11274 -005-2380-Z.

Song, Y., Z. Sun, C. Guo, Y. Wu, W. Liu, J. Yu, B. Menghe, R. Yang, and H. Zhang. 2016. Genetic diversity and population structure of Lactobacillus delbrueckii subspecies bulgaricus isolated from naturally fermented dairy foods. Sci. Rep. 6:22704. https://doi.org/10 $.1038 /$ srep22704.

Sun, Y. L., H. Tian, W. Fang, and G. C. Huo. 2012. Study on the key glycometabolism of Lactobacillus delbrueckii ssp. bulgaricus. Sci- ence and Technology of Food Industry 33:202-205, 209. https:// doi.org/10.13386/j.issn1002-0306.2012.22.057.

Wang, Q., Z. Zhang, X. Liu, J. Zhao, H. Zhang, and W. Chen. 2018. Fermentation characteristics of Lactobacillus bulgaricus and application in yak fermented milk. J. Food Sci. Technol. (Beijing) 36:53-63. https://doi.org/10.3969/j.issn.2095-6002.2018.01.007.

Wang, X., H. Ren, D. Liu, B. Wang, W. Zhu, and W. Wang. 2013. $\mathrm{H}+$-ATPase-defective variants of Lactobacillus delbrueckii ssp. bulgaricus contribute to inhibition of postacidification of yogurt during chilled storage. J. Food Sci. 78:M297-M302. https://doi.org/ 10.1111/1750-3841.12038.

Wu, S., Z. Zhu, L. Fu, B. Niu, and W. Li. 2011. WebMGA: A customizable web server for fast metagenomic sequence analysis. BMC Genomics 12:444. https://doi.org/10.1186/1471-2164-12-444.

Xu, Z., S. Li, G. Gong, Z. Liu, Z. Wu, and C. Ma. 2015. Influence of different acidifying strains of Lactobacillus delbrueckii ssp. bulgaricus on the quality of yoghurt. Food Sci. Technol. Res. 21:263-269. https://doi.org/10.3136/fstr.21.263.

Yekta, M., and S. Ansari. 2019. Jujube mucilage as a potential stabilizer in stirred yogurt: Improvements in the physiochemical, rheological, and sensorial properties. Food Sci. Nutr. 7:3709-3721. https:/ /doi.org/10.1002/fsn3.1230.

\section{ORCIDS}

Smith Etareri Evivie ㄴ https://orcid.org/0000-0002-4209-0978

Fei Liu (1) https://orcid.org/0000-0001-8827-4409

Bailiang Li ๑ https://orcid.org/0000-0002-4115-655X

Guicheng Huo 으 https://orcid.org/0000-0002-2617-9737 